\title{
Video head impulse test (vHIT): main concepts
}

Volume 4 Issue 5 - 2016

\begin{abstract}
Abbreviations: SCC, semi circular canals; VOR, vestibulo ocular reflex; ms, milliseconds; vHIT, video head impulse test; RALP, right anterior-left posterior; LARP, left anterior-right posterior
\end{abstract}

\section{Introduction}

Balance is maintained by a complex set of systems that include sensory input from proprioception, visual and vestibular system. The vestibular system has two parts: the otoliths (linear acceleration) and the semicircular canals (SCC) (head angular acceleration). This group of organs activates many reflexes, such the Vestibulo Ocular Reflex (VOR). This reflex is responsible to stabilized images on the retina during head movement by producing an eye movement in the opposite direction to head movement, thus preserving the image on the center of the visual field. It involves a 3-neuron arc that consists of the vestibular ganglion, vestibular nuclei, and oculomotor nuclei. With a latency period of only 8 to 12 milliseconds (ms), the VOR is considered the fastest reflex in humans.

Supported on this mechanism the VOR can be evaluated using an equipment for recording the movement of the eyes and find quantitatively responses about this reflex, based on the gain between eye velocity/head velocity. The normal value is equal one for healthy subjects.

\section{Concept}

Nowadays, it is observed a growing of test for vestibular system evaluation. One of them evaluates all semicircular canals and it is called video Head Impulse Test (vHIT). ${ }^{1}$ The vHIT allow the verification of the SCC dynamic function. It consists of monitoring eye movements as the patient fixates on a stationary target while the head is moved. The methodology is applying a passive high speed head rotation and immediately brief which permit a quantitative record by a digital video camera. ${ }^{2}$

After the test, besides the gain, it is possible to verify presence of normal or abnormal eye movements. As abnormal responses, catch up saccades, are classified as overt and covert saccades. Catch-up saccades reposition the eyes on the target. Overt saccades occur after head impulse and covert saccades typically occur toward the end of head impulses because of the saccadic latency. It is important to regard that covert saccades are very fast and they occur during the head rotation. Without the vHIT it is almost impossible to detect by the naked eye. As advantages of the test, could be mention that is have a lower cost, shorter test time, greater portability, and increased patient comfort, comparing to the others. But it is classified as a complementary test for the vestibular pathology diagnosis.

\section{Horizontal vHIT}

The responsible for the evaluation need to hold the head from the patient with both hands, and incline it 30 degrees to maintain the horizontal canal parallel the ground, permitting the best stimulation of them. Passive high speed head rotation around 5 to 10 degrees, alternating left and right at random mode. The patient would be able

\author{
Lilian Felipe \\ Department of Speech Pathologist and Audiology, Fluminense \\ Federal University, Brazil
}

Correspondence: Lilian Felipe, Health Institute from Nova Friburgo, Coordinator from Department of Speech Pathologist and Audiology, Fluminense Federal University, Rio de Janeiro, Brazil, Email lilian felipe@hotmail.com

Received: June 28, 2016 | Published: September 20, 2016

to keep the eyes fixed on target. It is important that the direction be unpredictable and timing. ${ }^{3}$

\section{Verticals vHIT}

The vertical canals paired are: right superior with left posterior and left superior with right posterior. This is explained because they lie in planes approximately 45 degrees to the sagittal plane of the head. Vertical head impulses were delivered by the clinician in the following manner: The patient was seated so that their body faced the target on the wall but with their head turned to be positioned about 35 degrees to the left for testing in the right anterior-left posterior (RALP) plane or 35 degrees to the right for testing the left anterior- right posterior (LARP) plane. ${ }^{4}$

\section{Conclusion}

The complexity of the human balance system creates challenges in diagnosis. The possibility of examining each of the six semicircular canals separately introduces a revolutionary change in clinical neurotology and may in time contribute to newer diagnostic possibilities, particularly when associated with the electrical responses of the saccule and utricle (cervical and ocular VEMP). ${ }^{5-8}$ But, is important to salient that, vHIT is a complementary test, which adds information for the vestibular evaluation.

\section{Acknowledgments}

None.

\section{Conflicts of interest}

Author declares there are no conflicts of interest.

\section{Funding}

None. 


\section{References}

1. MacDougall HG, Weber KP, McGarvie LA, et al. The video head impulse test: diagnostic accuracy in peripheral vestibulopathy. Neurology. 2009;73(14):1134-1141.

2. Weber KP, MacDougall HG, Halmagyi GM, et al. Impulsive testing of semicircular canal function using video-oculography. Ann N Y Acad Sci. 2009;1164:486-491.

3. Carey JP, Minor LB, Peng GC, et al. Changes in the three-dimensional angular vestibulo-ocular reflex following intratympanic gentamicin for Menière's disease. J Assoc Res Otolaryngol . 2002;3(4):430-443.

4. Schubert MC, Migliaccio AA, Della Santina CC. Dynamic visual acuity during passive head thrusts in canal planes. J Assoc Res Otolaryngol. 2006;7(4):329-338.
5. Cremer PD, Halmagyi GM, Aw ST, et al. Semicircular canal plane head impulses detect absent function of individual semicircular canals. Brain.

6. $1998 ; 121(\operatorname{Pt} 4): 699-716$.

7. Halmagyi GM, Weber KP, Aw ST,et al. Impulsive testing of semicircular canal function. In: Kaga \& Starr (Eds.), Neuropathies of the Auditory and Vestibular Eighth Cranial Nerves. Tokyo: Springer, Japan. 2009. p. 93-109.

8. Halmagyi GM, Weber KP, Curthoys IS. Vestibular function after acute vestibular neuritis. Restor Neurol Neurosci. 2010;28(1):37-46.

9. Halmagyi GM, Curthoys IS. A clinical sign of canal paresis. Arch Neurol. 1988;45(7):737-739. 